\title{
[ $\left.55^{6}\right]$
}

with bed-cloaths, the curtains of the bed being at the fame time drawn clofe, and the windows and doors of the room kept hut, with a great fire. He had fweated much the firt day, but the fweating having ftopped, his fkin became parched with heat, and he was feized with violent delirium. A phyfician who found hin in this ftate, opened the doors and windows of the apartment, put out the fire, and placed the patient upon the floor, in his thirt, clofe to the window. In a quarter of an hour the delirium went off, the patient feemed difpofed to heep, and foon recovered.

The Society give a fuccinct view of fimilar fevers as they have prevailed at different times. in different provinces of France. In all of thefe the utility of the antiphlogiftic plan of treatment, and the pernicious effects of a contrary method, were clearly afcertained.

\section{SECTION II.}

ESSAYS AND OBSERVATIONS.

1. Mijcellaneous Faits and Obfervations, comminicated in a letier to Dr. Simmons, F. R. S. by 


\section{[ 57$]$}

Thomas Percival, M. D. F. R. S. and S. A. Member of the Royal Medical Society at Paris, Ecc.

$7 \mathrm{HE}$ great Lord Verulam recommends 1 the collection of facts, experiments, and obfervations, as the beft method of promoting the improvement of Phyfic; and in his effays he exprefsly "confines himfelf to "certain brief " notes, fet down rather fignificantly, than "curiouny." This mode of writing is confonant to the plan of the Medical Journal, and is often more agreeable to men of letters, than long and fyftematic compofitions: for it pre-

- cludes the labour of reading or of repeating elementary propofitions, and well-known truths; renders the detection of error more eafy; facilitates the communication of new difcoveries; and prefents to the mind, in feparate and diftinct views, the real additions which are made to fcience*. How far the influence of thefe confiderations, or the fanction of the high authority I have quoted, may juftify the following mifcellaneous remarks, I thall leave to your decifion.

* See the Author's Preface to Philofophical, Medical, and Experimental Eflays.

$$
\text { Vot, IV. No I. H I. Retro }
$$




\section{$\left[\begin{array}{lll}5^{8} & ]\end{array}\right.$}

I. Retrograde motion of the Lymphatics.

A very ingenious young phyfician and philofopher, who, had he lived, wculd have done honor to his profeffion, has advanced a variety of arguments to evince a nearer communication between the alimentary canal and the bladder*, than by the fanguiferous circulation. The following cafes may, perhaps, illuftrate and confirm this doctrine.

Mrs. W - had laboured under a diarrbea many weeks, when $I$ was called to her affiftance on the $13^{\text {th }}$ of June 1780 . I directed for her the following pills :

3.. Extract. ligni Campech. gr. v.

Philon. Londinenf. gr. $x$.

Pulv. ipecac, gr. j.

Syrup. Cydon. q. $f$.

M. f. pil. iij. ter die fumendx.

By the ufe of thefe pills her diforder foon abated.

June 30 . She complained of naufea, heat, and thirft. The pulfe was not increafed in velocity, and the was ftill inclined to be lax. The following mixture was prefcribed:

* See Mr. Charles Darwin's Experiments, sc. Litchfield, printed 1780 . 


\section{[. $59-]$}

R. Aq. cinnam. ten. そvij.

Extract, ligni Campech, zj.

Sal. tart. Jiv.

Syrup: Cydon. ziij.

M. cap. $\zeta j$ js ter die in effervefcentia cum cochleare amplo fucci limonum.

This remedy feemed to obviate all her complaints. But in the morning of July the $5^{\text {th the }}$ had a fudden and urgent call to difcharge her urine; and after voiding treble the ufual quantity, The obferved, that it was of a pink colour, inclining to purple, very fimilar to that of the medicine which the had taken. I found her under fome alarm on account of this circumftance; and examining her water in a glafs, I was fatisfied that its hue was different from that of blood: and from the appearance I concluded, that it was ftrongly tinctured with logwood. In this opinion I was afterwards confirmed by its tafte, which was fweetin and fub-aftringent; and by the deep purple it affumed, when a fmall portion of the falt of fteel was added to it. The urine of this patient had not, during the previous courfe of her illnefs, varied from its natural colour, although eight fcruples of the extralum ligni Campecbenfis had been adminiiftered. About an hour before the prefent

\section{$\mathrm{H}_{2}$} fingular 


\section{[ 60,$]$}

fingular evacuation, the had taken the ufual dofe of her medicine, yet in the evening of the fame day, her urine exhibited no marks of the logwood.

In this cafe there appears to have been a fudden and copious tranflation of urine into the bladder, probably by means of the retrograde motion of the lymphatics : and the fluids, conveyed with the lacteals, were ftrongly imbued. with a medicine, which, together with its colouring particles, evidently retained alfo its aftringent quality *

September $27^{\text {th }}$ 1 780 . Mrs. C - had been ill more than two months of a pulmonary confumption, which was accompanied both with colliquative fweats and a diarrbcea, when I was confulted by her. I prefcribed a gentle emetic, and afterwards the following draughts:

B. Emulf commun, $\xi$ j.

Myrrh. mucilag. gum. arab. folut. gr. xij.

Elix. pareg.

Sp. nit dulc. aa. $3 ß$.

Sal. tart. $\exists$ j.

* Dr. Lewis, in his excellent Materia Medica, has ob. ferved, that logwood fometimes colours the urine, but he does not feem to have been apprized, that it communicates altringency to it. 


\section{[ $6 \mathrm{r}]$}

Succi limonum $3 ß$.

M. $f$, hauft ter die in effervefcentia fumend.

Her cough was alleviated, and the fweating and diarrbea almoft entirely reftrained by thefe. draughts. But during the ufe of them all the urine, which the voided, had the colour of $a$ dilute folution of logwood.

October $3 \mathrm{~d}$. The diarrbsa returned, and I had again recourfe to extractum ligni Campesbenfis, which was now given every fourth hour, in dofes: of fifteen grains, diffolved in fimple cinnamon. water. The purging was foon checked, and the urine affumed the fame pinky colour as before. A portion of it was turned black by immerfing in it the blade of a table knife: nor did the excretion change its appearance till the extract of logwood was laid afide.

This inftance of the uniform and permanent conveyance of a colouring aftrictive matter to the bladder, may perhaps feem lefs-favourable to the doctrine of a retrograde motion of the lymphatics, than the cafe before recited. But is it probable that fo large a quantity of logwood, retaining its peculiar and active properties, could have been introduced into the blood veffels, without occafioning fome unufual fymptoms? 


\section{[ 62 ]}

Or could the urine, in fo thort a fpace of time, have been replete with it, if it had been previoufly mixed with the whole mafs of circulating fluids? Be this, however, as it may, it is a curious and interefting fact, that a vegetable aftringent is capable of furmounting the powers of digeftion, of paffing into the abforbent veffels, and of being carried unchanged to the urinary organs. Various practical ufes may poffibly be founded upon it; and it may furnin a jufter theory of the action of the Peruvian bark, in glandular tumours, and diforders of the lymphatic fyftem. Certain it is, that this very efficacious medicine is remarkably retentive of its virtues. Fuller fays; with fome degree of admiration, Cum olim, experimenti caufa, ejufdem (corticis) decoxifem, non eo ufque vires ejus exbaurire valui, quin vel octavum decoitum adbuc amaricaret. If his patience had permitted him to extend the experiment, he would have found, as I have done*, that even twenty-five coctions, and thirty cold macerations, are infufficient to exhauft its virtues.

It is well known, that madder, taken internally, tinges the urine red; and that it produces a fimilar effect even upon the bones of animals,

* Efays, Medical and Experiment. vol. I.

though 


\section{[ 63 ]}

though neither the flefhy nor cartilaginous parts of the body fuffer any alteration by its ufe. Nor will the bones, when thus ftained, yield any colour to water or fpirit of wine. The root of this vegetable has a bitterifh, and fomewhat auftere tafte; but I have not yet afcertained, by any experiment, whether it impregnates the urine with an aftrictive quality. The colouring matter of rhubarb is fpeedily conveyed to the bladder; but the water thus imbued did not, in a late trial, exhibit the flighteft appearance of purple, on mixing with it a fmall quantity of the falt of fteel.

Little attention has hitherto been paid to the change of quality produced, by food or medicine, on the fecretions and excretions of the human body, although very ufeful information might be derived from it. Thus, for example, could we medicate the milk of nurfes, we thould be better qualified to cure the difeafes of the children whom they fuckle. There is a fpecies of foetid breath (dyfodia pulmonica), to which perfons of a narrow cheft and fcorbutic habit are peculiarly incident. It feems to originate from the want of power to make a full expiration, by which too much perfpirable matter is retained, and corrupted by ftagnation in the veficles. 


\section{[ 64 ]}

veficles of the lungs. In fuch cafes I have found the moit falutary effects from the ufe of myrrli and fixed air, internally adminiftered. Thefe fweetening and antifeptic fubftances are probably carried to the lungs, and difcharged together with the offenfive vapour, which they correct, at the fame time that they invigorate the fmalleft ramifications of the bronchix. For I cannot impute their action, folely at leaft, to their corroborant powers; becaufe neither fteel, the Peruvian bark, nor other tonics, are exhibited with the fame fuccefs.

It has been thewn above, that an aftringent fubftance may be conveyed to the bladder, fo as ftrongly to impregnate the urine. And there is no reafon to prefume, that this is owing to any particular fubtlety in the lignum Campecbenfe. Were proper tefts to be applied, the prefence of other remedies might, perhaps, be frequently difcovered in that recrementitious Huid. And thus we fhould have at command various means of cure, adapted to the diforders of thofe organs. In another work I have given a decifive proof, "that by drinking copiounly of mephitic water, the urine may be almoft faturated with fixed air,

* Philofophical, Med. and Experiment. Effays.

This 


\section{[ 65 ]}

This appeared from the precipitation which fuch urine produced in lime water, from the bubbles which it emitted, and from the folution of feveral calculi that were immerfed in it. And hence we have acquired the practical knowledge of a fafe and efficacious diffolvent, both of the ftone and gravel.

I thall clofe this fection with a paffage from Dr. Fuller, which, if it be the refult of accurate obfervation, corroborates what has been above advanced. Speaking of the balfam of Copaiba, he fays, "Sapore donatur amaro, acre, terebintbinaceo, admodum penetranti, et in ore durabili; atque licet videatur effe quadam terebintbine fpecies, urinam tamen odore violaceo minime inficit; illam vero Sapore amaro imbuit, ejufque et Seri Janguinis, et Salive muriaticam Salfedinem mirifice delet."

II, Reciprocal Sympatby between the Stomach and the Lungs.

A Gentleman, aflicted with a purulent expectoration, has found, by repeated experience, that his fits of coughing may often be fuppreffed by a draught of cold water, or a fmall glafs of wine. His courfe of life has been intemperate; and thefe remedies, by diminifhing the atonia of the ftomach, and producing a grateful fenfation

$$
\text { VOL, IV. N०I. }
$$




\section{[ 66 ]}

in that organ, allay, for a while, the irritation which fubfitts in the lungs. In fuch cafes of phthifis, which frequently occur, the exhibition of nitre, or other cold debilitating medicines, tends to aggravate the difeafe, and to haften its fatal termination. To patients, under thefe circumftances, porter is generally a very agreeable and falutary beverage. It quenches thirft; quiets the cough; checks the fweating; and, if drank only in fmall quantities at once, does not accelerate the pulfe, or augment the hectic fever.

Ann Ogden, aged ten years, was admitted an out-patient of the Mancheiter infirmary, and put under my care on the 22d of November 1779. On the 18 th the had been attacked with a moft pungent pain in the ftomach. The fucceeding day, a violent fpafmodic cough enfued, and her ftools were obferved to be bloody. She was foon relieved by opiates, mild purgatives, and a foft demulcent diet: for the fwallowing of a pin gave rife to thefe complaints; and the progrefs of them clearly evinces the fympathy which the lungs have with the ftomach. To this law of the animal oeconomy, phyficians and phyfiologitts have paid fufficient attention; but they have not equally noticed the reverfe of it; though it is no lefs certain, that various pulmonic 


\section{$\left[\begin{array}{lll}67 & \end{array}\right]$}

affections may powerfully influence the ftate of the ftomach; and that the confequent fymptoms furnifh very important indications of cure.

A phyfician confulted me, in February 1780 , on account of a fevere afthma, of the humoral kind, to which he was fubject. At the commencement of the difeafe, he could take feveral drachms of the vinum ipecacoanbe. But as his diforder increafed, the irritability of his Atomach became fo great, that fifteen drops of the fame wine often afted as an emetic. The medicine affording confiderable eafe to his breathing, he gradually augmented the dofe of it as he grew better, till he could bear a drachm or two without retching, and almoft without naufea.

$\mathrm{Mr}$ - in a fevere peripneumony, took, every fourth hour, two ounces of a decoction of feneka root and liquorice *: The remedy created no uneafinefs, and feemed to give relief, whillt the patient was in an erect pofture; but when he lay down, a pofition which rendered his

- The difagreeable fenfation, produced by the Seneka root, in the fauces, is much abated by combining with it, in decoction, a fufficient quantity either of the root or the extract of liquorice, the demulcent quality of which is an excellent auxiliary in the peripneumony. 


\section{[ 68 . $]$}

breathing more difficult, every dofe of it aggrayated the dyfpnoa.' In this inftance there feems to have been a reciprocal, or interchangeable action between the organs of digeftion and of refpiration. The increafe of dyfpnoea produced an increafe of irritaoility in the ftomach; and the feneka root, under thefe circumftances, proved, fo ftimulant as to aggravate the oppreffion of the lungs. This cafe, and I could cite many others, affords a ftrong confirmation of the propriety of Sydenham's practice, in keeping his peripneumonic and pleuretic patients out of bed as much as their ftrength would permit.

\section{Dyfury.}

Mr. - of Knutsford, applied to me in January 1782 for advice concerning an arthritic vertigo. I directed a blifter to the nape of his neck, and the following pills :

B. Gum. guaiac. $3 \mathrm{ij}$.

Sal. ammon. vol. $3 \mathrm{j}$.

Balfam guaiac. q. $f_{0}$,

M. f. pil. medioc. cap. iij. ter de die.

A violent ftrangury enfued. The medicine was difcontinued; the blifter removed; and thist painful complaint foon ceafed. In a few days the pills were repeated, but the firft dofe renewed 


\section{[ 69.]}

the affection of the urinary organs. A drachm of the species aromatice was then fubftituted in lieu of the volatile falt; and this formulary oct caftoned no pain or inconvenience. But having more confidence in the efficacy of the pills firft prefcribed, I advifed the further trial of then at the end of ten days : they produced, however, a third time the fymptoms of Atrangury, and were therefore entirely laid afide. Is it not probable, that in this cafe there was a tranfla tion of the gouty affection to the urinary paf fages, produced by the blifter, and augmented by the ftimulus of the volatile alkali? A predifpofition, being thus formed in thofe parts, the volatile falt alone proved afterwards fufficient to renew the malady.

There is a fpecies of chronic dyfury, to which perfons of an arthritic or fcorbutic habit, and who have paffed the meridian of life, are pecudiarly incident. It is often miftaken for the ftone, and aggravated by the ufe of lithontriptics. Indeed it has many fymptoms in common with that diforder; fuch as frequent and urgent calls to make water; pain at each extremity of she urethra; a mucous difcharge; tenefmus; and fometimes a fuppreffion of urine. But the patients, who labour under it, feel no uneafy weighs 


\section{[ 70 ]}

weight in the perinæum, and always void their water with much lefs difficulty in an ereet than in an horizontal pofture. The complaint, alfo, may be further diftinguifhed from the ftone by having fhorter intervals of eafe; by more fre quently injuring the retentive power of the bladder, and by occafioning no fudden interruption to the ftream of urine in the abfence of pain. It feems to arife from an acrid defluxion on the internal coat of the bladder, which is thereby rendered fo exquifitely fenfible, that the timulus of the urine becomes almoft intolerable, and very frequent efforts are excited to expel it: thefe efforts, however, fhould be reftrained as much as poffible, becaufe they tend to increafe the pain and irritation of the bladder, and to prevent the complete difcharge of its contents; for that organ cannot effectually contract itfelf without a due degree of previous diftenfion.

I have tried various remedies in this diforder, but have found none fo fuccefsful as mercury, which feldom fails to afford relief, and generally produces a cure, if adminiftered with perfeverance and in fufficient quantity. According to the urgency of the cafe, one, two, or three Scruples of the unguentum coruleum fortius thould be rubbed into the thighs every night, till a 


\section{[ 71 ] $]$}

light ptyalifm enfues: the fymptoms for the moft part abate before the fpitting comes on, and after it has continued a-while, they difappear entirely.

I was firt induced to adopt this mode of treatment from my experience of the falutary operation of the remedy recommended by $\mathrm{Dr}$. Gilchrift, in a diforder of the bladder, which bears fome analogy to that which I have defcribed *; but having found that the mercurial pill is apt to difturb the bowels, and confequently that it is lefs certain of admiffion into the fyftem, I have in my later practice preferred the ufe of the unguentum caruleum. In nighter cafes, indeed, I fometimes give half a grain of calomel, with two grains of James's fever powder, twice every day; and this fmall dofe of mercury, if duly continued, may fuffice to effect a cure, without producing any falivation, or even forenefs of the mouth. In a late inftance, an habitual head-ach, with which a difficulty and pain in making water were complicated, gave way to this remedy.

From the falutary operation of mercury in the dyfury, it may be fufpected, perhaps, that

? Phyficą and Literary Efrays, vol, iii. 


\section{[ $\left.7^{2}\right]$}

the difeale originated from the lues venerea. I formerly entertained this idea myfelf; but further experience has convinced me, that it has no foundation in more than half the cafes which occur; and confequently, in explaining the action of the remedy prefcribed, we muft not have recourfe to the fecret powers of a fpecific or an antidote.

Manchefter,

Feb. 26,1783 .

II. An account of a remarkable Frasture of the foull, by a pifol-ball, that entered the cranium $\therefore$ at the rigbt. temple and was fuccessfully extracted. By Mr. Cook, Surgeon at Barking in Effex. Communicated by $\mathrm{Dr}$. Onborn, Phyfician is London.

W the month of Auguft laft a blackfinith, of I the parifh of Dagenham in Effex, having taken the defperate refolution to thoot himfelf, applied a loaded horfe-piftol to his right temple. The ball entered the cranium, obliquely, at the os frontis, clofe to the os fphenoides, paffed along the infide of the cranium to the os frontis about 